Original Article

\title{
SOCIODEMOGRAPHIC PROFILE OF PATIENTS WITH ACUTE POISONING IN THE EMERGENCY WARDS OF A TERTIARY CARE HOSPITAL
}

\author{
SATHVIKA REDDY', DEVI REVATHI', V. LAKSHMI PRASANNA ${ }^{3}$, ARUNA C. RAMESH ${ }^{4}$
}

1,2,3 Department of Pharmacy Practice MS Ramaiah University of Applied Sciences Bangalore India, ${ }^{4}$ Professor and HOD Emergency Medicine-MS Ramaiah hospitals Bangalore

Email: sathvika.rdd@gmail.com

Received: 05 Mar 2018 Revised and Accepted: 27 Apr 2018

\section{ABSTRACT}

Objective: To assess the socio-demographic profile and outcomes in the patients with poisoning admitted to the emergency wards of a tertiary care hospital.

Methods: The prospective observational study was conducted for a period of six months in the emergency wards of a tertiary care hospital. The demographic data, hospital admission variables and outcomes were collected from various sources and documented. Cluster analysis was used to find the interaction between the socio-demographic and hospital admission variables in association with outcomes of poisoning.

Results: A total of 133 patients were admitted with acute poisoning. The mean age was $27.76 \pm 15.5 \%$. Females (51.1\%) were dominant over males (48.8\%). Incidents of poisoning were predominant in married (49.6\%), literates (41.35\%), abiding in urban region (86.4\%) and belonging to upper lower class (37.6\%). The poisonings were intentional (69.17\%) occurring through oral route $(81.2 \%)$ at home (82\%). Reason for poisoning was the most significant $\left(1.00^{*}\right)$ predictor followed by route of poisoning. Patients with mild symptoms were $85.71 \% 10.5 \%$ moderate and severe symptoms $3.75 \%$. Majority of the victims recovered $(82.71 \%)$ whilst $4.51 \%$ died.

Conclusion: Poisoning patterns vary with socio-demographic and socio-economic status, which is a prevalent social and economic issue in developing countries. Depression acts as a slow poison and is common among younger age groups leading to increased cases of intentional poisoning, thereby indicating a necessity for appropriate psychiatric counselling, medical and peer management strategies to identify the individuals in need that can reduce the risk of next attempt.

Keywords: Intentional Poisoning, Socio-demographic, Psychiatric counselling

(c) 2018 The Authors. Published by Innovare Academic Sciences Pvt Ltd. This is an open access article under the CC BY license (http://creativecommons.org/licenses/by/4.0/) DOI: http://dx.doi.org/10.22159/ijpps.2018v10i6.25653

\section{INTRODUCTION}

Worldwide intentional poisoning is one of the major causes of morbidity and mortality [1]. According to the World Health Organisation (WHO) 0.3 million people die due to various poisoning agents annually [2]. In India, five to six persons per lakh of the population die due to acute poisoning every year. However, the true magnitude of suicide remains an uncertain health issue due to lack of systematic profiling of risk factors associated with poisoning [3, 4].

People who indulge in self-harm are analytically heterogeneous and may display characteristics of mental issues. Factors such as lower socioeconomic status, emotional disturbances, chronic diseases, distress due to loss of business, the stress of examinations, unemployment, marital disharmony and family problems can lead to poisoning $[4,5]$.

The manner of poisoning differs with age. In the paediatric age group poisoning normally arises due to accidental ingestion of commercial and harmful household products such as mothballs, flea and tick product, cleaning solutions, nail polish remover and thinner whilst in the adolescents and adults, the common mode of poisoning was intentional which occurred by consumption of medications, organophosphorus compounds and harmful household products or sanitary products [6]. The key determinants of poisoning associated deaths are due to changes in lifestyle and social behaviour, rapid industrialisation, massive use of pesticides in agriculture, increased availability of drugs and chemical substances $[3,7]$.

The choice of poisoning agents depends upon the socio-economic factors, demographic factors and individual medical factors which greatly varies from country to country. Hence the profile of poisoned victims, toxic agents and their treatment outcomes are necessary for the development of regional or national poison policies $[8,9]$.
There is a lack of sample registration system for poisoning cases in India. Previous studies have reported only about the demographic factors and their association with the poisoning outcome but there exists a complex interaction among socio-demographic variables that need to be evaluated to identify the most important predictors associated with poisoning.

Against this background, the study aimed to determine the profile and outcomes of acute poisoning in patients admitted to the emergency wards of a tertiary care hospital.

\section{MATERIALS AND METHODS}

\section{Study site and duration}

This prospective observational study approved by the institutional ethics committee (Registration No: ECR/215/Inst/Ker/2013) was conducted for a duration of six months (November 2016-April 2017) in the emergency wards of a tertiary care hospital located in the North of Bangalore chiefly catering to the demands of the urban population.

\section{Inclusion and exclusion criteria}

A total of 1538 medicolegal cases were observed within a time period of six months among which 1331 cases were excluded as they were with self-inflicted wounds, burns, injuries, ingestion of nondigestible substances such as pins, coins and plastics, vehicular accidents, suspected murder, sexual assault and criminal abortion. About 207 cases of acute poisonings were brought directly or transferred from other hospitals or emergency teams. As a part of the ethical requirement written informed consent was obtained from the 133 poisoning victims, approval from the remaining 74 patients wasn't possible due to reasons such as critical condition, extent of willingness of the victim to provide the poisoning details, 
hospitalisation during the night and discharges against medical advice due to lack of availability of beds and other reasons.

\section{Data collection}

A structured validated proforma was suitably designed, the data regarding the demographic details, mode of poisoning, route and location of poisoning, hospital admission characteristics and outcomes of the poisoning victims were collected and recorded by a trained investigator.

\section{Sources of data}

The patients admitted with acute poisoning received first aid in the emergency wards and were further managed by shifting them to intensive care unit/wards depending on their condition. Relevant patient's information was obtained from various sources such as patient's case records, medication charts, laboratory data, medicolegal case registers and by self-interviewing the victims who were in a state of providing response (one to one interview) followed by their caretaker/families regarding the past history, circumstances that led to poisoning and emotional disturbances along with information regarding contents of the poisoning agent, severity of the poisoning, treatment being provided from the healthcare professionals. This data contributed meaningfully and effectively towards the study and was documented by a trained investigator into the proforma and transcribed into a database created using Microsoft Access.

\section{Variables}

The variables selected included patient sociodemographic variables such as age, gender, marital status, the location of residence, level of education, occupation and social class that was obtained from all the patients included in the study. Age was categorised as $\leq 30 \mathrm{y}$ and $>30 \mathrm{y}$, gender was noted as male or female, the location of residence as urban and sub-urban, marital status as married and unmarried, level of education as illiterate and literate, occupation as homemakers, job holders, self-employed, agriculturist, students, retired and according to the Kuppuswamy's socio-economic scale social class was classified as upper, upper middle, upper lower, lower. Hospital admission variables included reason for poisoning, location of exposure, route of poisoning, hospitalisation time after exposure, number of days in the hospital, mental illness, co-morbidities and the consciousness of the victim on time of admission assessed based on the Glasgow Coma Scale and outcomes of the acute poisoning in patients were categorised as recovered, death, discharge against medical advice.

Glasgow coma scale

\begin{tabular}{lll}
\hline Eye-opening response & Verbal response & Motor response \\
\hline $4=$ Spontaneous & $5=$ Oriented & $6=$ Obeys commands \\
$3=$ To verbal stimuli & $4=$ Confused & $5=$ Localises pain \\
$2=$ To pain & $3=$ Inappropriate words & $4=$ Withdraws from pain \\
$1=$ None & $2=$ Incoherent & $3=$ Flexion to pain or decorticate \\
& $1=$ None & $2=$ Extension to pain or decerebrate \\
\end{tabular}

\section{Data analysis}

To examine whether there was interaction among the sociodemographic and hospital admission variables over time for the poisoning as outcome variables, a series of chi-square analyses were conducted across the dataset. To examine whether clusters of patients could be identified, a two -step cluster analysis was carried out on the dataset using SPSS 22.0 (SPSS, Inc, Chicago IL, USA). The two-step cluster analytic method was chosen as it allows for the identification of groups in datasets containing both categorical and continuous variables, and without having to preselect the number of clusters. Step 1 involved pre-clustering in which the original variables were 'sorted' into pre-clusters. Step 2 involved standard hierarchical clustering on the pre-clusters formed in Step 1 based on Schwartz's Bayesian Information Criterion (BIC). The number of clusters was chosen based on a change in BIC being small between adjacent clusters. Examination of the silhouette cfefient, which contrasts the average distance to elements in the same cluster with the average distance to elements in other clusters which should be $\geq 0.02$. Between-cluster tests for a variable were not significant, the cluster analysis was rerun with the variable deleted. In this way, this iterative process looked for the most relevant variables which would add to an interpretable solution. Accordingly, several analyses were run for selection of variables and a number of variables were excluded as they were not found to be important in cluster partitioning. Later chi-square tests to identify the importance of variables in a cluster and indicate signi ficant dfferences between clusters.

\section{RESULTS}

A total of 133 acute poisoning patients hospitalized during the study period in the emergency department of a tertiary care hospital were analysed.

\section{Sociodemographic characteristics}

The poisoning cases were classified as per age, gender, marital status, occupation, educational background, the location of residence, socio-economic stratum (table 1). Among the total study population,77(57.89\%) patients were $\leq 30 \mathrm{y}$ with a mean age of $27.76 \pm 15.5$. Poisoning was equally distributed among both females (51.1\%) and males (48.8\%). Married groups (49.6\%) outnumbered the unmarried (36.0\%). Regarding the occupation status majority of the patients were homemakers (27.6\%) tailed by job holders (25.56\%). However, in light with education, incidents were higher in patients with higher level of education $(41.35 \%)$ and residing in urban areas (86.4\%) Kuppuswamy's Socio-economic Scale was utilised and poisoning was predominant in the upper lower class (37.6\%) and lower middle (29.31\%).

\section{Hospital admission characteristics}

Study background of poisoning displayed $67.4 \%$ cases were of suicidal intent with the major route of exposure being ingestion (81.2\%). The incidents of poisoning significantly occurred at home $(82.0 \%)$ when compared to the workplace $(10.5 \%)$. The time of exposure to the poisoning agent was in the evening hours (30.53\%) and with regard to the time elapsed from the toxic agent exposure to hospitalisation, $66.2 \%$ arrived at the hospital in a time duration $\geq 1$ hour. The hospital stays of the patients admitted with poisoning ranged between a minimum of $1 \mathrm{~d}$ to a maximum of $18 \mathrm{~d}$ (in a victim with acid ingestion) where $65.4 \%$ were in the hospital for $\leq 1 \mathrm{~d}$. Among the total poisoning victims, $13 \%$ were diagnosed to have psychiatric abnormalities such as depression, schizophrenia and bipolar disorders. Comorbidities such as endocrinological, hepatic, renal, neurological, haematological, respiratory, cardiovascular and urological disorders were observed in $27 \%$ (table 2). The severity of poisoning was determined using the Glasgow Coma Scale and a majority of the patients with mild and moderate symptoms recovered. The outcomes among the poisoning victims revealed recovery in $110(82.7 \%)$ followed by $17(12.7 \%)$ discharge against medical advice and 6 (4.51\%) death (fig. 1).

Significant difference between cluster $1(\mathrm{~N}=45)$ and cluster 2 $(\mathrm{N}=88)$, was found regarding gender $(\chi 2=7.25, \mathrm{p}=0.007)$, marital status $\left(\chi 2=29.11, \mathrm{p}<0.001^{*}\right)$, location of residence $(\chi 2=9.90$, $\left.\mathrm{p}=0.001^{*}\right)$, reason of poisoning $\left(\chi 2=103.5, \mathrm{p}<0.001^{*}\right)$ and location of poisoning $\left(\chi 2=24.13, \mathrm{p}<0.001^{*}\right)$ (table 3$)$.

The contribution of socio-demographic and attendance variables to the cluster formation was evaluated and predictor importance for each variable on outcome was determined. Reason for poisoning had highest significant predictor importance followed by the route of poisoning and marital status. Age was the least significant among the predict. 
Table 1: Demographic characteristics

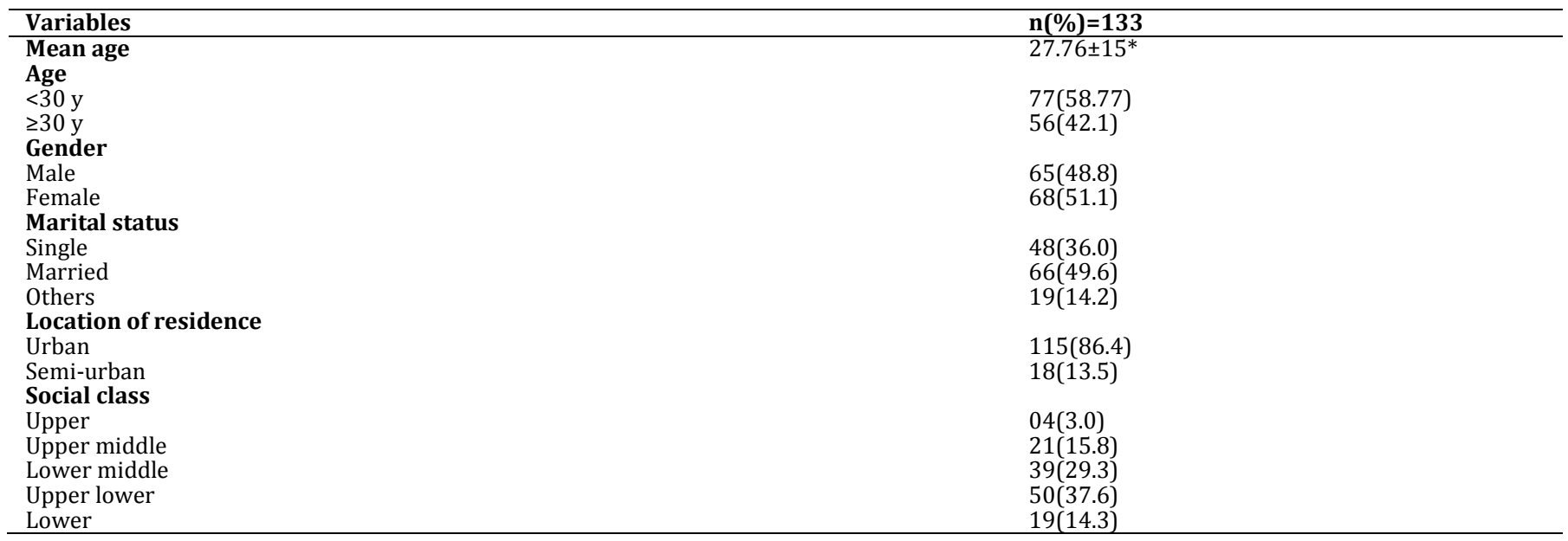

${ }^{*}$ mean $\pm \mathrm{SD}{ }^{*} \mathrm{n}=$ Number of participants

Table 2: Hospital admission characteristics

\begin{tabular}{|c|c|}
\hline Variable & $n(\%)=133$ \\
\hline \multicolumn{2}{|l|}{ Reason for poisoning } \\
\hline Intentional & $92(69.17)$ \\
\hline Non-Intentional & $41(32.6)$ \\
\hline \multicolumn{2}{|l|}{ Route of poisoning } \\
\hline Ingestion & $108(81.2)$ \\
\hline Other route & $25(18.8)$ \\
\hline \multicolumn{2}{|l|}{ Location of exposure } \\
\hline Home & $109(82.0)$ \\
\hline Workplace & $14(10.5)$ \\
\hline Others & $10(7.5)$ \\
\hline \multicolumn{2}{|l|}{ Hospitalisation time after exposure } \\
\hline$\leq 60 \mathrm{~min}$ & $45(33.8)$ \\
\hline$>60 \mathrm{~min}$ & $88(66.2)$ \\
\hline \multicolumn{2}{|l|}{ No. of days in hospital } \\
\hline$\leq 1 \mathrm{~d}$ & $87(65.4)$ \\
\hline$>1 \mathrm{~d}$ & $46(34.5)$ \\
\hline \multicolumn{2}{|l|}{ Mental illness } \\
\hline Present & $13(9.7)$ \\
\hline Absent & $120(90.3)$ \\
\hline \multicolumn{2}{|l|}{ Comorbidities } \\
\hline Present & $36(27.0)$ \\
\hline Absent & $97(73.0)$ \\
\hline
\end{tabular}

Table 3: Characteristics of the two clusters

\begin{tabular}{|c|c|c|c|c|}
\hline Variables & Cluster $1 \mathrm{n}(\%)=45$ & Cluster 2 n (\%) = 88 & Chi square value & P-value \\
\hline Mean age* & $26.63 \pm 21.57$ & $29.58 \pm 10.4$ & - & - \\
\hline \multicolumn{5}{|l|}{ Gender } \\
\hline Male & $29(64.4)$ & 35 (39.8) & 7.2597 & $.007 *$ \\
\hline \multirow{2}{*}{\multicolumn{5}{|c|}{ Marital status }} \\
\hline & & & & \\
\hline Single & $09(20.0)$ & $40(45.4)$ & 29.1159 & $<0.001^{*}$ \\
\hline Married & $19(42.2)$ & $45(51.2)$ & & \\
\hline Others & $17(37.7)$ & $03(3.4)$ & & \\
\hline \multicolumn{5}{|l|}{ Location of residence } \\
\hline Urban & $34(75.5)$ & $83(94.3)$ & 9.9044 & $0.001 *$ \\
\hline Semi urban/rural & $11(24.5)$ & $05(5.7)$ & & \\
\hline \multicolumn{5}{|l|}{ Mental illness } \\
\hline Present & $04(8.9)$ & $11(12.5)$ & 0.388 & 0.533 \\
\hline Absent & $41(91.1)$ & $77(87.5)$ & & \\
\hline \multicolumn{5}{|l|}{ Comorbidities } \\
\hline Present & $11(24.5)$ & $25(28.4)$ & 0.2371 & 0.626 \\
\hline Absent & $34(75.5)$ & 63 (71.6) & & \\
\hline \multicolumn{5}{|l|}{ Reason for poisoning } \\
\hline Intentional & $06(13.3)$ & $87(98.8)$ & 103.5724 & $<0.001^{*}$ \\
\hline Non-Intentional & $39(86.7)$ & $01(01.2)$ & & \\
\hline \multicolumn{5}{|l|}{ Location of exposure } \\
\hline Home & $26(57.8)$ & $83(94.3)$ & 24.13 & $<0.001 *$ \\
\hline Workplace & $10(22.2)$ & $04(4.54)$ & & \\
\hline Others & $07(15.5)$ & $03(3.4)$ & & \\
\hline \multicolumn{5}{|l|}{ Route of poisoning } \\
\hline Ingestion & $22(48.8)$ & $88(100)$ & - & - \\
\hline Other route & 23 (51.1) & $0(0)$ & & \\
\hline
\end{tabular}

${ }^{*}$ mean $\pm S D ;{ }^{*}$ = Number of participants 


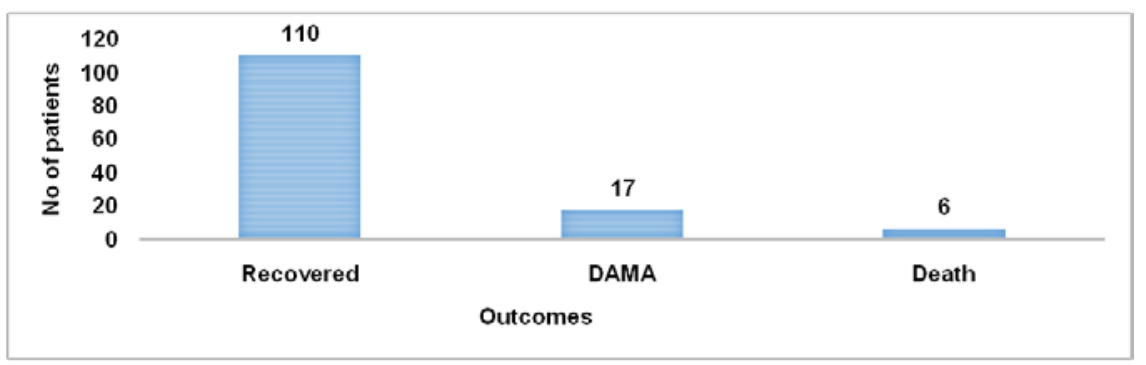

Fig. 1: Outcomes of poisoning patients, *DAMA: discharge against medical advice

Table 4: Contribution of socio-demographic and attendance variables to the cluster formation

\begin{tabular}{ll}
\hline Variable & P-imp \\
\hline Reason for poisoning & $1.00^{*}$ \\
Route of poisoning & $0.54^{*}$ \\
Marital status & $0.28^{*}$ \\
Location of poisoning & $0.21^{*}$ \\
Residence location & $0.12^{*}$ \\
Gender & $0.10^{*}$ \\
Number of days in hospital & $0.04^{*}$ \\
Mental health & $0.03^{*}$ \\
Age & $0.02^{*}$ \\
Comorbidities & 0.01 \\
Glasgow coma scale & 0.01 \\
Hospitalisation time after exposure & 0.01 \\
Social class & 0.01 \\
\hline
\end{tabular}

P-imp, predictor importance; ${ }^{\mathrm{P}}<0.01$, Cluster $1=45(33.8 \%)$, Cluster $2=88(66.2 \%)$

\section{Predictor Importance}

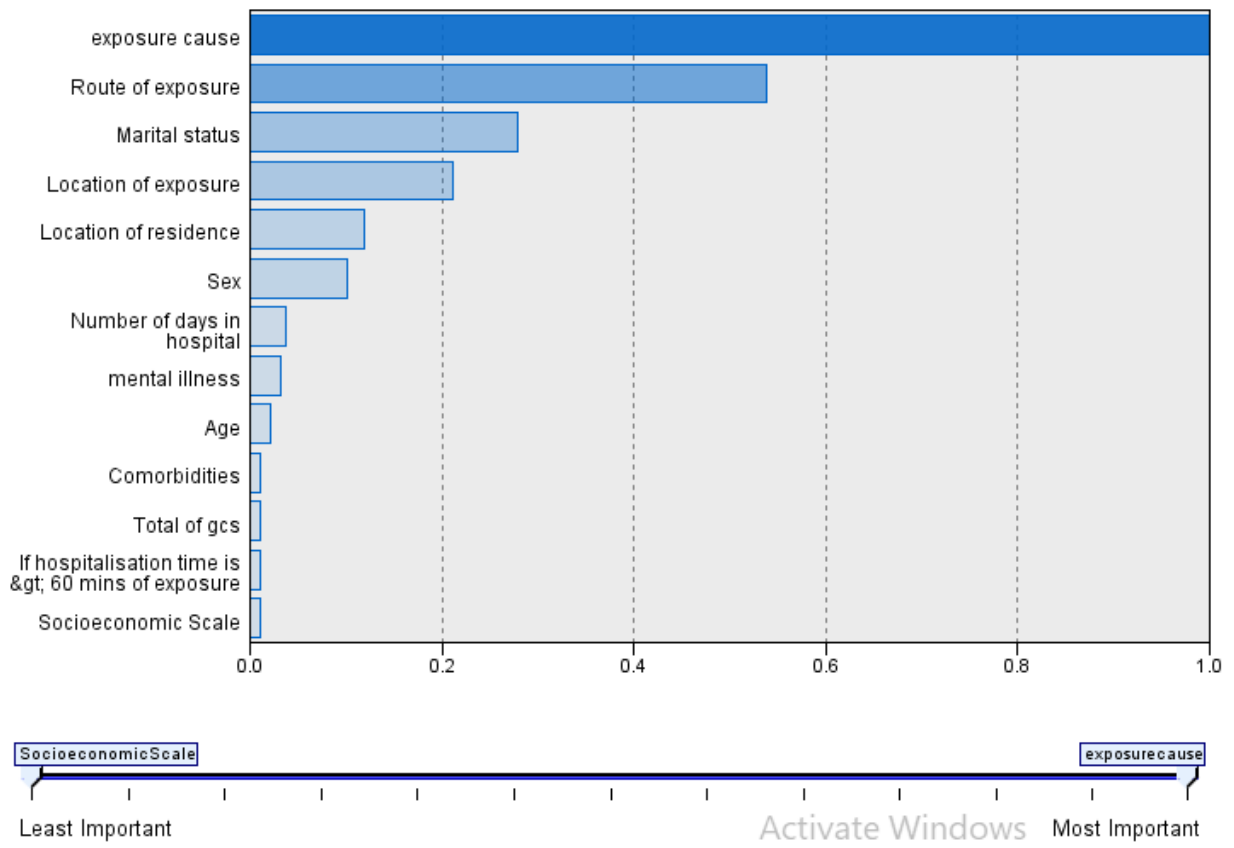

Fig. 2: Predictor importance of data variables

\section{DISCUSSION}

In developed countries, the rate of mortality from poisoning is testified to be $1 \%$ to $2 \%$ which is comparatively less to developing countries like India where more than 50,000 deaths occur due to toxic exposure $[10,11]$. Karnataka places fourth in the list of states with a high rate of suicides, while Bangalore records the second highest in the cities [12]. Data from previous studies in India have provided information regarding the direct association of demographic factors with the outcomes. Even though previous studies had described the socio-demographic profile of the poisoning victims, none have sought to investigate the clusters of the 
victims in a way that allows identifying the relationship between the socio-demographic and hospital admission characteristics that can influence the outcome of poisoning. We assumed the demographic variables alone to be insufficient, hence conducted the study to understand the interaction between the demographic and hospital attendance characteristics along with the most important predictor associated with poisoning.

The National Survey on Drug Use and Health (2009-2014) data indicate 18-25 y old had higher percentages of suicidal thoughts and attempts compared to middle-aged adults (45-to 64-year olds) [13]. In this study younger patients were significantly observed as the majority of the poisoning cases ranged in the age groups $30 \mathrm{y}$ (57.89\%). A pattern similar to this has been reported in Indian studies $[14,15]$. As young adults progress through generations, their traditional households generally get less supportive of their choices pertaining to financial social sectors, marriage age, premarital sex, rehabilitation, stress in academics as well as inability in achieving the targets in professional and educational fronts [16]. With regard to the predictor importance in our study age was found to be least significant, hence we can't always attribute the reason for poisoning to age due to changing trends in the recent times where members from all age groups are equally prone to suicide attempts. Gender differences were found to be a significant predictor in this study and females $(51.1 \%)$ outnumbered males $(48.8 \%)$ contrary to most studies in India [17, 18]. Nonetheless, a study conducted by Heyerdahl et al., in Oslo [19] displayed poisoning to be slightly higher in females than males which could be due to emotional instability, depression, physical abuse, forced marriages and postpartum psychosis [20].

In Indian studies, poisoning is commonly seen in married groups which were the third most important predictor as observed in this study findings $(49.6 \%)[21,22]$. This can be attributed to factors such as family disharmony, marital violence, dowry issues, the concept of joint family over nuclear family setups leading to a financial burden and stress $[23,24]$. Contrast to our results was a study conducted in Mysore which displayed poisoning incidents in unmarried than married [25]. The study site is located in an urban area and catering its services mainly to urban population had the majority of the poisoning cases significantly from urban areas $(86.4 \%)$ and found to be the significant predictor. This was in accordance with studies conducted in a similar setting $[26,27]$ while contradictory to the findings from a previous study conducted in a rural setting (55.4\%) [28]. With regard to occupation, homemakers $(27.06 \%)$ and other vulnerable groups such as job holders (25.56\%) were found in higher numbers due to reasons such as familial disharmony, dowry-related issues, stress and strain in work. These results were comparable to a study by Devendranath et al., whilst contrary to a study where students outnumbered the other classes $[29,30]$. The fact that in this study predominant cases were from an urban background, poisoning was observed more in literates $(41.35 \%)$ which reflects the transition in the Indian society along with higher stressors commonly in this group. Findings from other studies were concurrent with our results [23,31]. According to data from different researchers in India numerous cases of poisoning occur in lower socioeconomic class and middle-class families as low economic status has an adverse impact on a person's self-esteem and may confront to problems such as crime, violence, unemployment, financial hardship, disorder personality which can despair their emotions and can potentially induce self-harm behaviour, similarly, our results had cases from upper lower (37.6\%) and lower middle class (29.3\%) [16, 32] (table 1).

In light with the reason for poisoning several studies in developed and developing countries reported the commonest mode of toxicity to be suicidal $[33,34]$ however, most of the childhood poisonings were non-intentional and occurred in studies conducted in other parts of the world $[35,36]$. The type of poisoning in our study was significantly intentional $(69.17 \%)$ and the most important predictor. Increase in suicide endeavours could be because of settlement issues, lack of emotionally supportive network, illegitimate pregnancy, divorce, personal dissatisfactions, and insufficiency to adapt to some quick circumstances [24,29]. The main route was oral ingestion $(81.2 \%)$ and exposure to the poisoning agents at home
(82\%) were important predictors among the study participants which was in line to the results obtained by other researchers [37, 38]. To avoid unnecessary attention majority of the patients have consumed poison in the evening hours $(30.53 \%)$. This pattern of exposure to the toxic agent correlated to a study by Leena Antony et al., [27]. The time elapsed between the intake of poison and arrival of the victim to the hospital was observed to be>1 hour (66.1\%) concurrent to the findings by Ahmed et al., while a study conducted in Nepal had more than one-third of the patients arriving within an hour of exposure [39, 40]. Delay in the admission to the hospital can be attributed to traffic-related issues, lack of ambulance facilities, a referral from other centers, insufficient knowledge regarding the incident of poisoning and responding to the victim in trouble as soon as possible. The early arrival of the patient to the hospital diagnosis and can reduce the chances of mortality.

The duration of the hospitalisation for the patients is one of the predictors in our study ranged between 0-18 d. and most of them were hospitalised for $\leq 1 \mathrm{~d}(65.4 \%)$. These findings were similar to a study conducted in the western part of India [41].

Majority of people who experience a mental illness do not die by suicide. However, of those who die from suicide, more than 90 percent have a diagnosable mental disorder which is frequently undiagnosed, or untreated [42]. In India, there is variation in the type and frequency of psychiatric disorders. Our study findings displayed mental illness (9.7\%) like depression, bipolar disorders and schizophrenia to be a significant predictor which was parallel to results from various literature where people suffering from psychological disorders are more prone to suicidal attempts due to emotional instability [23, 43]. Poisoning victims with a history of endocrinological, hepatic, renal, neurological, respiratory, haematological, cardiovascular, urological and other disorders were $27 \%$. Physical illnesses are usually associated with chronic, unremitting pain, restriction in physical mobility and recreational activities hence these complications make this group vulnerable to suicide endeavours. The severity of poisoning in the victims was assessed using the Glasgow Coma Scale and the majority of the patients presented with mild $(85.71 \%)$ to moderate symptoms (10.57\%) similar to a study conducted by Shoba Churi et al., in Mysore [5] (table 2).

The studies conducted all over the world [33, 40,44, 45] were parallel to our findings in which out of the total 133 poisoning cases $110(82.71 \%)$ recovered, $17(12.7 \%)$ were discharged against medical advice and 6 (4.51\%) deaths in total (fig. 1). As a majority of the patients recovered, decreased mortality could be due to appropriate emergency and intensive care management facilities in the hospital.

Firstly, the cluster analysis is an essential technique for classifying the demographic and hospital admission characteristics into predictive groups. Table 3 indicates a significant difference between both the clusters: cluster $1(\mathrm{n}=45)$ and cluster $2(\mathrm{n}=85)$. From table 4 the predictor importance was determined and the reason for poisoning had the highest significance while age was the least significant (fig. 2).

\section{LIMITATIONS}

The study was conducted for a short duration and all the patients were not referred for psychiatric counselling hence there was a lack of psychiatric details collected.

\section{CONCLUSION}

The present data gave an insight that intentional poisoning was the most important predictor of poisoning followed by the route of poisoning and marital status. There exists a significant interaction between sociodemographic and hospital attendance variables which influence the outcomes of poisoning.

Strict rules and regulation to restrict the over the counter sales of pharmaceutical products and toxic agents should be initiated.

The initiation of poison information centres or helplines in the country is necessary as they offer free, confidential and expert medical advice that helps in earlier management by providing inhome treatment to the victims. The poison information centres in 
hospitals are used for the health care providers to keep themselves updated regarding the recent management techniques in poisoning cases. The country should also develop special ambulances that attend immediately when the poison helpline rings with antipoisoning gear and first aid kits as traffic-related issues can cause a delay in the management to the victims which could be fatal.

High rates of intentional poisoning were observed among young adults residing predominantly in urban areas due to expanding stress in life, unemployment, changing lifestyles, financial hardship, life settlement issues thus suicide preventive measures such as peer support programs, training community and family members, crisis centres and helplines, identify adolescents and adults and refer them to mental health care centres should be initiated.

"What people never understand is that depression is is n't about the outside, it's about the inside". Depressive condition acts a slow poison and thus it is important to ensure appropriate psychiatric counselling to such patients to reduce the risk of the next episodes.

\section{ABBREVIATIONS}

GCS: Glasgow Coma Scale

DAMA: Discharge Against Medical Advice

\section{ACKNOWLEDGEMENT}

We acknowledge Dr. V. Madhavan, Dean and Principal, Dr. E. Maheswari, Professor and Head of Department of Pharmacy Practice, Faculty of Pharmacy, M. S. Ramaiah University of Applied Sciences, Dr Vijay Sharma, Dr Aruna C Ramesh Head of the Department Emergency Medicine MS Ramaiah Memorial and Teaching Hospitals Bangalore.

\section{FUNDING OR OTHER COMPETING INTERESTS}

This research did not receive any specific grant from funding agencies in the public, commercial, or not-for-profit sectors.

\section{DISCLOSURES}

The authors declare no conflict of interest. All the authors declare that they had no financial, personal relations towards other organisations whose interest could have affected the content of the article in either positive or negative way.

\section{AUTHORS CONTRIBUTIONS}

Dr Sathvika and Dr Revathi wrote the primary draft of this paper, which was edited by Mrs. Lakshmi Prasanna Marise for essential content. Dr. Aruna C Ramesh helped with the review of the paper for improved quality. All the authors reviewed and provided comments on further iterations.

\section{CONFLICT OF INTEREST}

"The author(s) declare(s) that there is no conflict of interest regarding the publication of this paper."

\section{REFERENCES}

1. Jesslin J, Adepu R, Churi S. Assessment of prevalence and mortality incidences due to poisoning in a South Indian tertiary care teaching hospital. Indian J Pharm Sci 2010;72:587-91.

2. Ahuja H, Mathai AS, Pannu A, Arora R. Acute poisonings admitted to a tertiary level intensive care unit in northern India: patient profile and outcomes. J Clin Diagn Res 2015;9:UC01-4.

3. B Maharani, N Vijayakumari. Profile of poisoning cases in a Tertiary care Hospital, Tamil Nadu India. J Appl Pharm Sci 2013;3:91-4.

4. Kar N. Profile of risk factors associated with suicide attempts: a study from Orissa, India. Indian J Psychiatry 2010;52:48-56.

5. Churi S, Ramesh M, Bhakta K, Chris J. Prospective assessment of patterns, severity and clinical outcome of Indian poisoning incidents. Chem Pharm Bull (Tokyo) 2012;60:859-64.

6. Harish D, Chavali KH, Singh A, Kumar A. Recent advances in the management of poisoning cases. J Indian Acad Forensic Med 2011;33:74-9.
7. Abd-Elhaleem ZA, Muqhem BA. Pattern of acute poisoning in $\mathrm{Al}$ Majmaah region, Saudi Arabia. Am J Clin Exp Med 2014;2:79-85.

8. Singh O, Javeri Y, Juneja D, Gupta M, Singh G, Dang R. Profile and outcome of patients with acute toxicity admitted in intensive care unit: experiences from a major corporate hospital in urban India. Indian J Anaesth 2011;55:370-4.

9. Hameed FA, Ansari HK, Al-Najjar FJ. Prevalent poisonings in adolescents and adults in dubai: a compendium from rashid hospital. Asia Pac J Med Toxicol 2014;3:115-9.

10. Singh B, Unnikrishnan B. A profile of acute poisoning at Mangalore (South India). J Clin Forensic Med 2006;13:112-6.

11. Panda BB, Hansda MK, Mishra K, Samantsinghar P. Study of poisoning cases in an Indian tertiary care teaching hospital. J Indian Acad Forensic Med 2015;37:165-8.

12. Prakruti PK. Bengaluru records second-highest rate of suicide in the country. Bangalore Mirror Bureau; 2015.

13. National Survey on Drug Use and Health(NSDUH). Available from: https://www.samhsa.gov/data/population-data-nsduh. [Last accessed on 04 Mar 2018]

14. Prajapati T, Prajapati K, Tandon R, Merchant S. Acute chemical and pharmaceutical poisoning cases treated in civil hospital, Ahmedabad: one year study. Asia Pac J Med Toxicol 2013;2:63-7.

15. Maheswari E, Abraham L, Chacko CS, Saraswathy GR, Ramesh AC. Assessment of pattern, severity and outcome of poisoning in the emergency care unit. J Appl Pharm Sci 2016;6:178-83.

16. Ramesha KN, Rao KB, Kumar GS. Pattern and outcome of acute poisoning cases in a tertiary care hospital in Karnataka, India. Indian J Crit Care Med 2009;13:152-5.

17. Ramesh V, Chavan VR, Arshad M, Raghunandan M. Faizuddin. A study on the pattern of acute poisoning in an emergency department of a tertiary care hospital. Asian J Pharm Clin Res 2016;9:361-3.

18. Srinivasa V, Kavya ST, Madhumathi R, Dudhwewala A. Profile of poisoning in a tertiary care hospital. Int J Basic Med Sci 2012;3:135-9.

19. Heyerdahl F, Hovda KE, Bjornaas MA, Nore AK, Figueiredo JC, Ekeberg 0 , et al. Pre-hospital treatment of acute poisonings in Oslo. BMC Emerg Med 2008;8:15.

20. Vijayakumar L. Suicide in women. Indian J Psychiatry 2015;57 Suppl 2:S233-S238.

21. Nair PK, Revi NG. One-year study on pattern of acute pharmaceutical and chemical poisoning cases admitted to a tertiary care hospital in thrissur, India. Asia Pac J Med Toxicol 2015;4:79-82.

22. Acharya S, Lakshminarayana K, Sharanappa M. Assessment of poisoning cases in a tertiary care hospital. Int J Biomed Res 2014;5:578-81.

23. Ramdurg S, Goyal S, Goyal $\mathrm{P}$, Sagar $\mathrm{R}$, Sharan $\mathrm{P}$. Sociodemographic profile, clinical factors, and mode of attempt in suicide attempters in consultation-liaison psychiatry in a tertiary care centre. Ind Psychiatry J 2011;20:11-6.

24. Indu TH, Raja D, Ponnusankar S. Toxicoepidemiology of acute poisoning cases in a secondary care hospital in rural South India: a five-year analysis. J Pstgrad Med 2015;61:159-62.

25. Patil A, Peddawad R, Verma VCS, Gandhi H. Profile of acute poisoning cases treated in a tertiary care hospital: a study in Navi Mumbai. Asia Pac J Med Toxicol 2014;3:36-40.

26. Aravind A, Rai M. Pattern of acute poisoning admissions in the medical intensive care unit of a tertiary care hospital. Int J Pharm Sci Drug Res 2014;6:239-42.

27. Anthony L, Kulkarni C. Patterns of poisoning and drug overdosage and their outcome among in-patients admitted to the emergency medicine department of a tertiary care hospital. Indian J Crit Care Med 2012;16:130-5.

28. Bari MS, Chakraborty SR, Alam MM, Qayyum JA, Hassan N, Chowdhury FR. A four-year study on acute poisoning cases admitted to a tertiary hospital in Bangladesh: emerging trend of poisoning in commuters. Asia Pac J Med Toxicol 2014;3:152-6.

29. Sarkar D, Shaheduzzaman M, Hossain MI, Ahmed M, Mohammad N, Basher A. Spectrum of acute pharmaceutical and chemical poisoning in northern Bangladesh. Asia PacJ Med Toxicol 2013;2:2-5. 
30. Thapa SR, Lama P, Karki N, Khadka SB. Pattern of poisoning cases in emergency department of kathmandu medical college teaching hospital. Kathmandu Univ Med J 2008;6:209-3.

31. Gargi J, Rai H, Chanana A, Rai G, Sharma G, Bagga IJ. Current trends of poisoning-a hospital profile age. J Punjab Acad Forensic Med Toxicol 2003;69:30-88.

32. Datir S, Petkar M, Farooqui J, Makhani C, Hussaini SN, Chavan K, Bangal R. Profile of acute poisoning cases at pravara rural hospital, Loni. J Indian Acad Forensic Med 2015;37:400-4.

33. Teklemariam E, Tesema S, Jemal A. Pattern of acute poisoning in Jimma University Specialized Hospital, South West Ethiopia. World J Emerg Med 2016;7:290-3.

34. Datir SB, Petkar M, Farooqui JM, Makhani CS, Hussaini SN, Chavan KD, et al., Study of outcome in acute poisoning cases in rural region of Western Maharashtra. J Forensic Leg Med Title 2015;24:1-7.

35. Manikyamba D, Madhavi N. Clinical profile of poisoning in children admitted in a tertiary care centre. Int J Sci Res $2015 ; 4: 2$.

36. Hassan BA, Siam MG. Patterns of acute poisoning in childhood in Zagazig, Egypt: an epidemiological study. Int Sch Res Notices 2014.

37. Sulaj Z, Prifti E, Demiraj A, Strakosha A. Early clinical outcome of acute poisoning cases treated in intensive care unit. Med Arch 2015;69:400-4.
38. Mbarouk GS, Sawe HR, Mfinanga JA, Stein J, Levin S, Mwafongo $\mathrm{V}$, et al. Patients with acute poisoning presenting to an urban emergency department of a tertiary hospital in Tanzania. BMC Res Notes 2017;10:482.

39. Al-Barraq A, Farahat F. Pattern and determinants of poisoning in a teaching hospital in Riyadh, Saudi Arabia. Saudi Pharm J 2011;19:57-63.

40. Paudyal BP. Poisoning: pattern and profile of admitted cases in a hospital in central Nepal. JNMA J Nepal Med Assoc 2005;44:92-6.

41. Asari PD, Shah SM, Amin AJ, Patel ND. Drug utilization study on acute poisoning cases treated at a tertiary care hospital in western part of India. Asia Pac J Med Toxicol 2016;5:20-4.

42. Mental Health Reporting-Facts About Mental Illness and Suicide. Available from: http://depts.washington.edu/ mhreport/facts_suicide.php. [Last accessed on 01 Mar 2018].

43. Maskey A, Parajuli M, Kohli SC, Baral S, Basnet S, Poudel N. Scenario of poisoning cases in adults admitted in Manipal Teaching Hospital, Pokhara, Nepal. NJMS 2012;1:23-6.

44. Asawari R, Atmaram P, Bhagwan K, Priti D, Kavya S, Jabeen GA. Toxicological pattern of poisoning in urban hospitals of Western India. J Young Pharm 2017;9:315-20.

45. Alzahrani SH, Alqahtani AH, Farahat FM, Elnour MA, Bashawri J. Drug poisoning and associated factors in Western Saudi Arabia: a five-year retrospective chart review (2011-2016). Pak J Med Sci 2017;33:1188-93. 